\title{
Forearm Support Band Versus Wrist Splint in Treatment of Lateral Epicondylitis
}

\author{
Hamza M Shaheen ${ }^{1 *}$, Nadia Fayaz ${ }^{2}$, Lilian Albert Zaky ${ }^{2}$ and Ayman \\ Mansour ${ }^{3}$ \\ ${ }^{1}$ Department of Physiotherapy, Faculty of Allied Medical Sciences, Palestine Ahlyia \\ University, Bethlehem, Palestine \\ ${ }^{2}$ Department of Musculoskeletal Disorders and its Surgery. Faculty of Physical \\ Therapy, Cairo University, Egypt \\ ${ }^{3}$ Department of Orthopedic Surgery. Faculty of Medicine and Surgery, Cairo \\ University,Egypt
}

*Corresponding Author: Hamza M Shaheen, Department of Physiotherapy, Faculty

of Allied Medical Sciences, Palestine Ahlyia University, Bethlehem, Palestine

DOI: 10.31080/ASOR.2020.03.0200

\begin{abstract}
Objective this study was done to assess the therapeutic efficacy of forearm support band and wrist splint in minimizing severity of pain and improving hand grip strength with lateral epicondylitis cases, and determine which one of these two common splints is more effective to reduce pain intensity and improve grip strength.

Method: Thirty male and female patients with tennis elbow were selected from orthopedic Department at National instate of neurolocomotor system. All patients were randomly assigned into two groups. The group (A) (n = 15, mean age: $44.8 \pm 6.87$ years) received forearm support band for four weeks, while the group (B) ( $n=15$, mean age: $42.86 \pm 6.34$ years) received wrist splint. All patients received exercises (12 sessions, 3 sessions per week) over a four weeks period. They were evaluated using visual analog scale to determine the pain intensity, and handheld dynamometer to determine hand grip strength in both groups.

Results: The results of the current study revealed that forearm support band or wrist splint combination with exercises for four weeks in patients with tennis elbow resulted in significant increase in hand grip strength in the post-treatment, associated with a significant decrease in pain intensity in the post-treatment in both groups. In addition, it revealed that there was significant difference between forearm support and wrist splint as regard to pain reduction which wrist splint allows a greater degree of pain relief than the forearm support band for patients with lateral epicondylitis, while there was no difference as regard to grip strength improvement between both groups.

Conclusion: It was concluded that forearm support band or wrist splint (cock-up splint) combined with exercises were effective in improving pain intensity and increasing hand grip strength in patient with tennis elbow, and wrist splint allows a greater degree of pain relief than the forearm support band.
\end{abstract}

Keywords: Lateral Epicondylitis; Exercises; Forearm Support Band; Wrist Splint

\section{Introduction}

Lateral epicondylitis is a painful condition affecting the tendinous tissue of the origin of the wrist extensor muscles at the lateral epicondyle of the humerus, leading to loss of function of the affected limb [1].
Tennis elbow begins as a micro tear of the tendinous origin of the wrist extensor muscles and results in degeneration and reactive granulation tissue formation. The mechanical failure of the tendon results in a tendinitis and symptoms of tennis elbow such as radiating humeral lateral epicondyle pain [2]. 
This overuse syndrome is characterized by pain and tenderness below the lateral epicondyle, which is exacerbated when subjected to a resisted wrist extension. People who engage in the repetitive hand tasks are more susceptible to this type of injury. This injury occurs in $1-3 \%$ of the general population; however, this increases to more than $50 \%$ in tennis players and population that use regular repetitive hand functions [3].

Treatment of tennis elbow has different theoretical mechanism of actions, Common rehabilitation modalities are utilized as ultrasound, electrical stimulation, Extracorporeal shockwave therapy (ESWT), friction massage, stretching and strengthening exercise [4].

Stretching and strengthening programs are common components of most therapy programs. Therapists also use other modalities, including iontophoresis, low-level laser therapy, and hyperthermia [5].

Orthotic devices are commonly used as a treatment strategy for lateral epicondylitis, they aims primarily to attack the cause of lateral epicondylitis by reducing the overload forces [6]. Twenty-one percent $(21 \%)$ of the patients with a tennis elbow are prescribed an elbow support [7].

Conservative physical therapy management is considered to be the first choice of treatment for lateral epicondylitis [8]. To prevent and treat this condition, it is considered necessary to reduce passive and active stresses applied to the origin of the extensor carpi radialis brevis (ECRB). To achieve this, elbow band (strap) is a common device which is worn below the elbow. It applies a binding force over the wrist extensor muscle mass at their proximal origin (this is also known as a counterforce orthosis). It has been substantiated, that such a band can reduce the percentage of the elongation and force generation made by musculotendinous fibers above the orthosis [9].

The wrist extensor muscles act as stabilizers during gripping and other hand functions. Keeping the wrist in extension is thought to have lower physiologic demands on the muscles and therefore reduces the overloading strain on the tissues $[10,11]$.

The primary goal of wrist splinting lateral epicondylitis is to decrease the pain and inflammation at the origin of the extensor carpi radialis brevis (ECRB) [12]. The wrist cock-up splint is one of the most common splints used, this rigid orthosis maintains the wrist in extension to offload the extensors of the forearm and promote healing at the muscle origin. The appropriate posture of the wrist in the splint has been described in various positions, ranging from 0 to 45 degrees of extension [13].

\section{Question of the study}

Is there a significant difference between the use of forearm support band and wrist splint on pain intensity and hand grip strength in patient with lateral epicondylitis?

\section{Purpose of the Study}

The purposes of the study were:

- $\quad$ To assess the therapeutic efficacy of forearm support band and wrist splint in minimizing severity of pain and improving hand grip strength in lateral epicondylitis cases.

- To determine which one of these two common splints is more effective to reduce pain intensity and improve grip strength.

\section{Significance of the Study}

Many elbow injuries and conditions that initially appear mild and easily managed can cause permanent disability with inadequate treatment. Lateral and medial epicondylitis are 2 such conditions that are common in overhead athletes and athletes who repeated extension of the wrist against resistance [14].

Tennis elbow is a common diagnosis. It affects $1 \%$ to $3 \%$ of the adult population, occurs mainly as episodes in the dominant arm of patients aged 35 to 50 years. The pathophysiologic mechanism of tennis elbow was unclear, which may be the reason why there is no consistently effective treatment for the condition, especially over the long term that is supported by scientific evidence [15].

Lateral elbow pain is an extremely common presentation among manual workers. The most common cause is an overuse syndrome related to excessive wrist extension [16].

There is still no scientific evidence to support the idea that which of a cock-up splint or elbow band is more effective as treatment for lateral epicondylitis [6].

There is conflicting evidence on the effects of counterforce orthoses on grip strength and pain. Several authors have reported 
increased grip strength and reductions in pain and disability [17]. While others have reported no significant differences in pain-free grip strength or pain [18].

Therefore, there is a great need to compare between different modalities that have been proven to be effective in treating tennis elbow. Until now up to researchers knowledge, no study has compared between forearm support band and wrist splint to find out which is more effective in providing faster improvement regarding reduction of pain and improvement of hand grip strength.

So the results of this study may provide a base line for physiotherapist, physicians and all fields of sports medicine in prevention and management of tennis elbow, as well as to improve hand grip strength and decrease pain in tennis elbow patients and tennis players.

\section{Delimitations}

This study was delimited to following aspects

- Thirty patients diagnosed by orthopedist as lateral epicondylitis of both sexes were selected for this study.

- Their ages ranged from 30 - 55 years old.

- $\quad$ Pain intensity was assessed by Visual Analogue Scale (VAS).

- $\quad$ Grip strength was assess by hand held dynamometer.

\section{Limitation}

This study was limited by the following factors:

- $\quad$ Small sample size.

- Individual variations.

- $\quad$ Possible errors during measurement procedures.

\section{Basic assumptions}

It was assumed that:

- $\quad$ Patients reported truly their pain intensity during assessment.

- $\quad$ Patients did not take any medications during the study.

- $\quad$ All patients avoided strenuous activities of the upper limbs that may aggravate the lesion.

- All patients received the same routine of physical therapy approach.
- $\quad$ All equipments that are used in this study are reliable and valid.

\section{Hypotheses}

It was hypothesized that:

- There was no significant effect of forearm support band on pain severity and hand grip strength in tennis elbow patients.

- There was no significant effect of wrist splint on pain severity and hand grip strength in tennis elbow patients.

- There was no significant difference between forearm support band and wrist splint on pain severity and hand grip strength in tennis elbow patients.

\section{Patients and Methods}

The current study was designed to determine the therapeutic effectiveness of forearm support band and wrist splint in minimizing pain intensity and improving hand grip strength in tennis elbow cases.

\section{Patients}

- $\quad$ Thirty male and female patients with age from 30-55 years suffering from lateral epicondylitis participated in this study.

- All patients were randomly assigned by orthopedic surgeon.

Groups of the study

Patients were divided into two groups:

- Group (A) (Forearm band): Fifteen patients received forearm band combined with exercises for 12 sessions over a four weeks period, for three sessions each week.

- $\quad$ Group (B) (Wrist splint): Fifteen patients received wrist splint combined with exercises for 12 sessions over four weeks period, for three sessions each week.

The two groups were matching in gender, age, weight, height, and body mass index (BMI).

\section{Criteria for patients selection}

Inclusion criteria:

- $\quad$ Age ranged from 30 to 55 years.

- $\quad$ Chronic pain over lateral epicondyle.

- Dominant hand affected. 


\section{Exclusion criteria:}

- $\quad$ Patients with polyarthritis, carpal tunnel syndrome, rotator cuff tendonitis, cervical spondylosis and neurological abnormalities in affected area.

- Osteoporotic and rheumatoid arthritic patients.

- $\quad$ Old fracture of the affected arm.

- Serious elbow injury at the time of treatment.

\section{Instruments}

Instruments used in this study were divided into following discussed below.

\section{Instruments for assessment}

\section{Hand held dynamometer}

The hand held dynamometer was used to provide a detailed and objective measurement of wrist joint strength throughout its range of motion, the pressure being registered in kilogram (Kg). It gives better information about the state of the joint and serves as a motivator for improvement as patient can see the scale movement and try to move it more. Hand held dynamometer was proved to be reliable in the measurement of hand grip strength in tennis elbow [19]. The dynamometer consists of an adjustable handle that can be placed in several grip positions and a calibrated gauge to show the measured value of force (usually in Kg) (Figure 1).

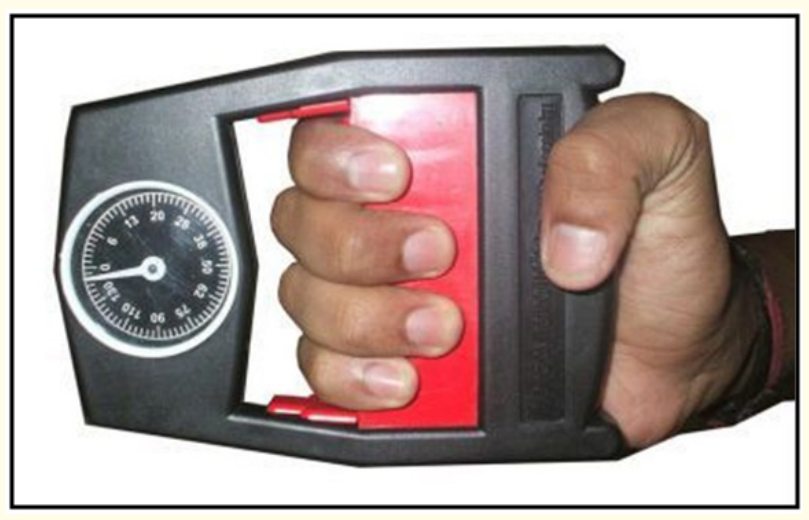

Figure 1: Hand held dynamometer.

\section{Visual analogue scale (VAS)}

It is a graphic rating scale, which is commonly interpreted as a valid report of pain intensity and was used to record the degree of pain intensity. VAS (Appendix III) is a-10 cms line, at one end, it was written (no pain = zero) and at the other end, it was written (worst pain $=10$ ). Each subject was asked to mark and score on the line at the point that represent intensity of pain [20].

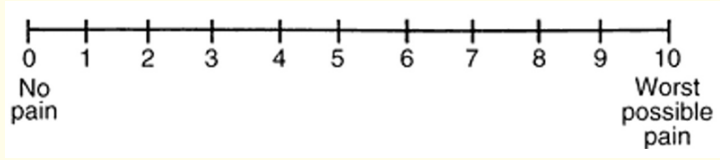

Figure a

\section{Instruments for treatment}

The forearm support band (counterforce brace)

The counterforce brace is simple in design and comfortable to wear, mad from nylon-packed foam rubber with Velcro support strap, which is worn on the forearm under the lateral epicondyle of the humerus. It decreases the force of the muscle contraction by inhibiting muscle expansion and reducing tension at the musculotendinous unit proximal to the band [21]. The counterforce brace essentially changes the functional origin of the extensor mass to a site distal to the radial head. This may assist in resting common extensors tendons origin to permit healing [21,22] (Figure 2).

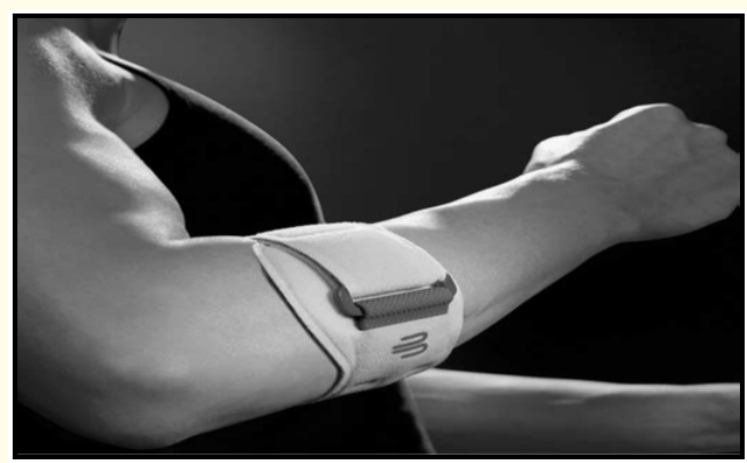

Figure 2: The forearm support band or counterforce brace [17].

\section{Wrist cock-up splint}

The wrist cock-up splint is one of the most common splints used, this rigid orthosis maintains the wrist in extension to off load the extensors of the forearm and promote healing at the muscle origin [13]. 
The wrist splint is made of neoprene and incorporated a rigid polyethylene bar anteriorly to hold the wrist in $20^{\circ}$ extension and prevent flexion or other wrist movements. It is applied to the palmar surface of the forearm, wrist, and hand, and extended from the metacarpophalangeal crease to two thirds of the way up the forearm and is fastened with 3 straps (Figure 3).

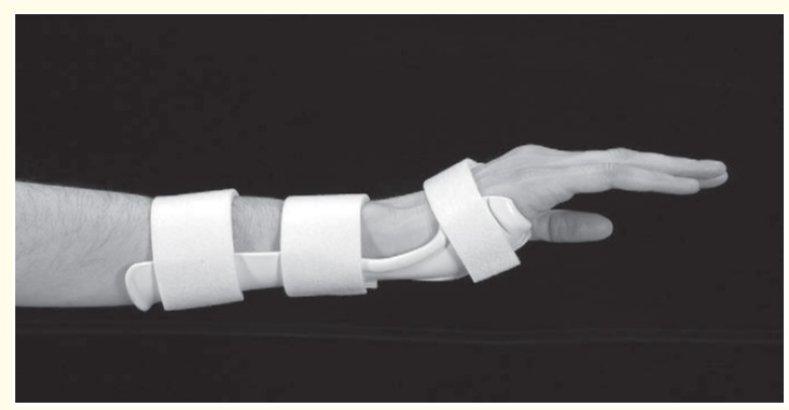

Figure 3: Wrist cock-up splint [17].

\section{Procedures of the study}

All patients of the study were informed about the study steps, and the expected benefits were explained before signing the informed consent. All patient included in this study signed an informed consent. The procedures of the study was divided into the main two categories:

\section{Assessment procedures}

\section{Assessment of pain intensity: (During Thomson test)}

Thomsen test was performed by active dorsiflexion of the wrist of the affected arm against resistance with the patient comfortably sitting, elbow extended and forearm pronated [23]. The intensity of pain was measured during the test with a visual analogue scale (VAS) from 0 to 10 , with 0 indicating no pain, and 10 indicating worst pain. The patient was asked to make a mark on this line, then the line is measured and recorded in millimeters or centimeters.

\section{Assessment of hand grip: (Using hand held dynamometer)}

The hand held dynamometer was used to provide a detailed and objective measurement of wrist joint strength (grip strength) throughout its range of motion, the individuals were sitting with their shoulder adducted and neutrally rotated, elbow flexed at $90^{\circ}$, forearm in neutral position, and wrist between $0^{\circ}$ and $30^{\circ}$ dorsiflexion and between 0 o and 150 ulnar deviation. After the individual is positioned properly, tell him, "Squeeze as hard as you can harder relax." Record the scores of three successive trials for the hand tested.

\section{Treatment procedures}

Thirty patients were randomly assigned into two groups:

- Therapeutic procedures of group (A): The forearm support band group. The size of the band was selected according to each patient and placed $2.5 \mathrm{~cm}$ distal to lateral epicondyle. Patients were asked to wear the brace continuously during daytime for the 4 weeks intervention period, and just removed at session time and during sleep.

- $\quad$ Therapeutic procedures of group (B): The wrist cock-up splint group. the size of the splint was selected according to each patient, hold the wrist in $20^{\circ}$ extension and prevent flexion or other wrist movements. Patients were asked to wear the brace continuously during daytime for the 4 week intervention period, and just removed at session time and during sleep.

Both groups received progressive strengthening and stretching exercises programme based on the work of Pienimaki., et al. (1996) and Struijs., et al. (2004) [17,24].

\section{Exercises program: Procedures for both groups}

Exercises performed for both groups included: Four-step exercises programme. Each step was performed in one week for four weeks [17].

\section{Step 1}

\section{Slow fist clenching}

Patient was in sitting position, elbow extended, forearm rested on the treatment table and comfortably pronated. The patient was asked to clench his hand eight counts (times) (Figure 4).

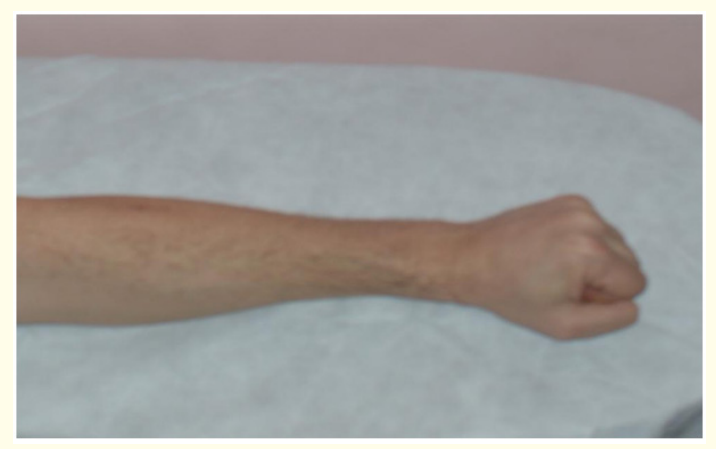

Figure 4: Clenching fist strongly. 


\section{Resisted wrist extension}

Patient was in sitting position, elbow extended, forearm pronated and rested on the treatment table. The therapist's one hand applied resistance on the dorsal surface of the patients hand and the other hand supported above the wrist. The patient was asked to extend the wrist counting to eight (Figure 5).

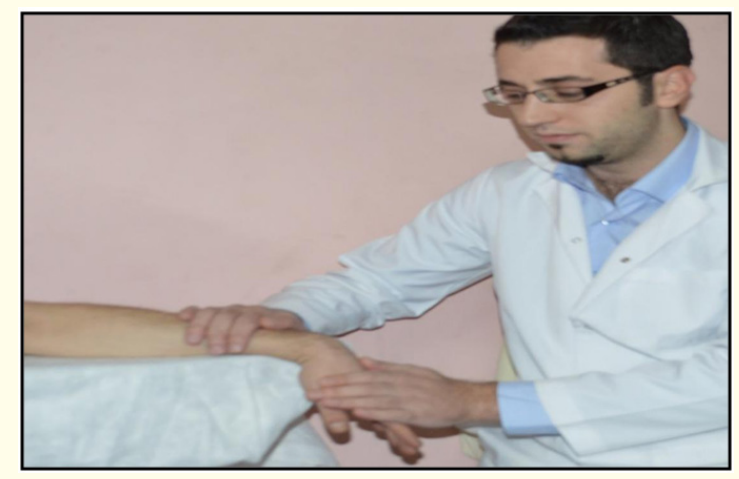

Figure 5: Resisted wrist extension.

\section{Resisted wrist flexion}

Patient was in sitting position, wrist extended, forearm pronated and rested on the treatment table. The therapist's one hand applied resistance on the palmar surface of the patient hand and the other hand supported above the wrist. The patient was asked to flex the wrist counting to eight (Figure 6).

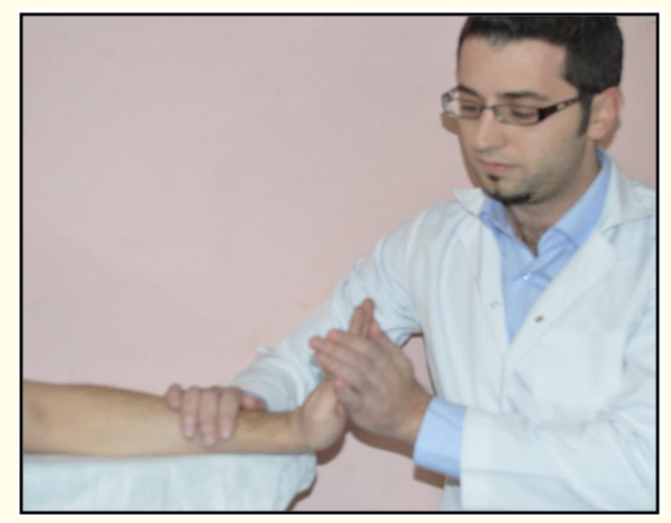

Figure 6: Resisted wrist flexion.
At the end of the session gentle stretching exercises for wrist flexors and wrist extensors muscles were made. The elbow should be extended and not flexed to increase the amount of stretch as required. These stretches should be held for 20-30 seconds (Figure 7 and 8).

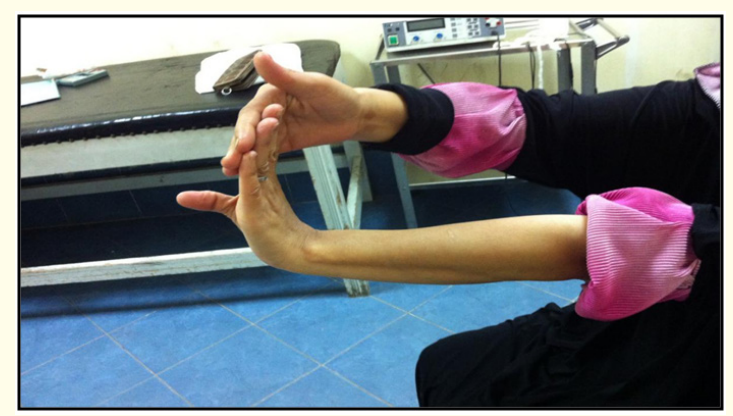

Figure 7: Stretching for wrist flexors.

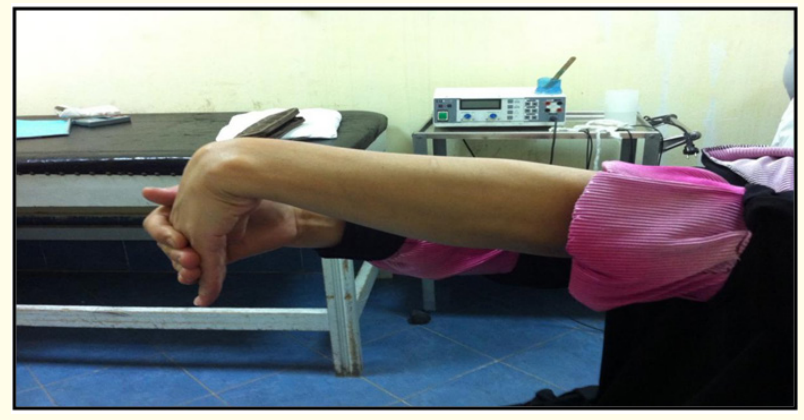

Figure 8: Stretching for wrist extensors.

N.B Vigorous stretching should be avoided and the patient should not stretch to the point of pain that reproduces symptoms. The first step was performed for ten repetitions for all exercises in the first step.

\section{Step 2}

Exercises against an elastic band for wrist flexion

Patient was in sitting position, elbow semiflexed, forearm pronated and rested on the treatment table. Elastic band's one end was attached above. The patient was instructed to flex his wrist with holding the other end of the band. The duration of exercise was performed the patient counted to eight and relaxed (Figure 9). 


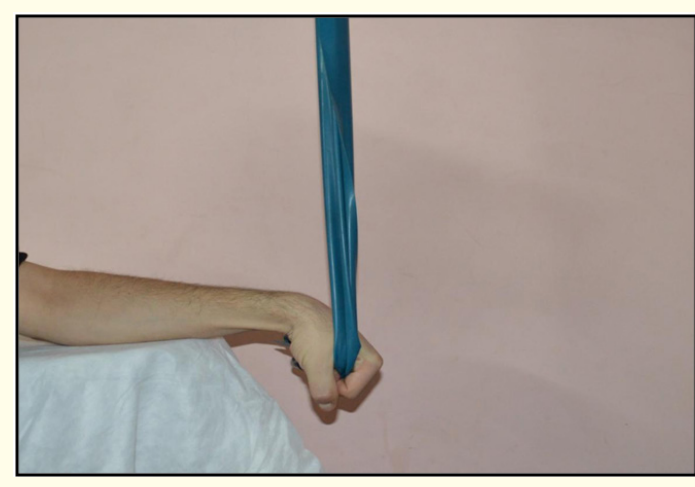

Figure 9: Wrist flexion against an elastic band.

\section{Exercises against an elastic band for wrist extension}

Patient was in sitting position, elbow semiflexed, forearm pronated and rested on the treatment table. Elastic band's one end was attached below to the leg of treatment table. The patient was instructed to extend his wrist with holding the other end of the band. The duration of exercise was performed as the patient counted to eight and relaxed (Figure 10).

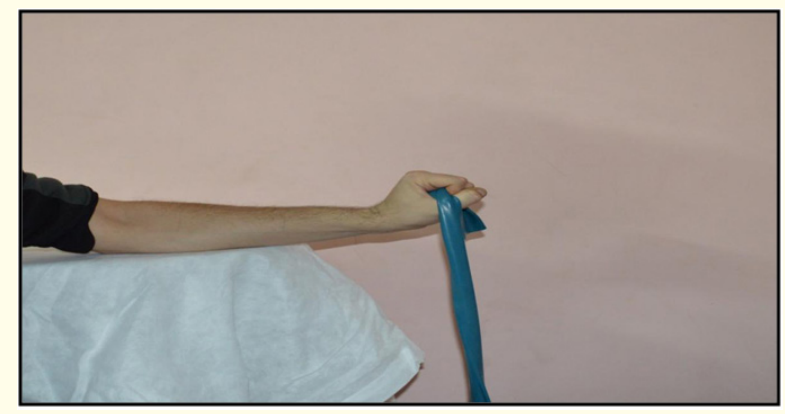

Figure 10: Wrist extension against an elastic band.

\section{Exercises against an elastic band for wrist ulnar deviation.}

Patient was in sitting position, elbow semiflexed, forearm in midposition and rested on the treatment table. Elastic band's one end was attached above to the window. The patient was instructed to ulnar deviate his wrist with holding the other end of the band. The duration of exercise was performed as the patient counted to eight and relaxed (Figure 11).

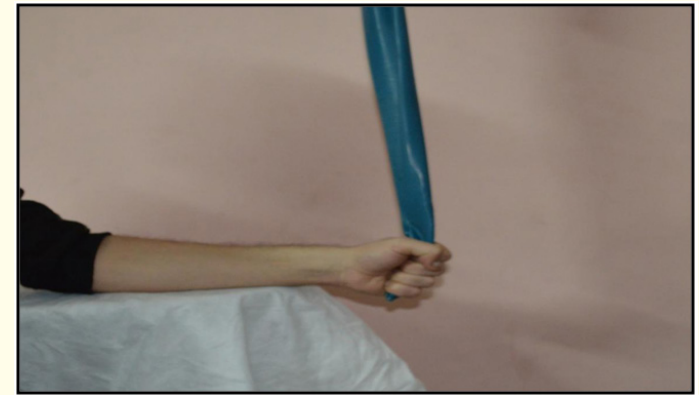

Figure 11: Wrist ulnar deviation against an elastic band.

\section{Exercises against an elastic band for wrist radial deviation}

Patient was in sitting position, elbow semiflexed, forearm in midposition and rested on the treatment table. Elastic band's one end was attached below to the leg of treatment table. The patient was instructed to radial deviate his wrist with holding the other end of the band (Figure 12).

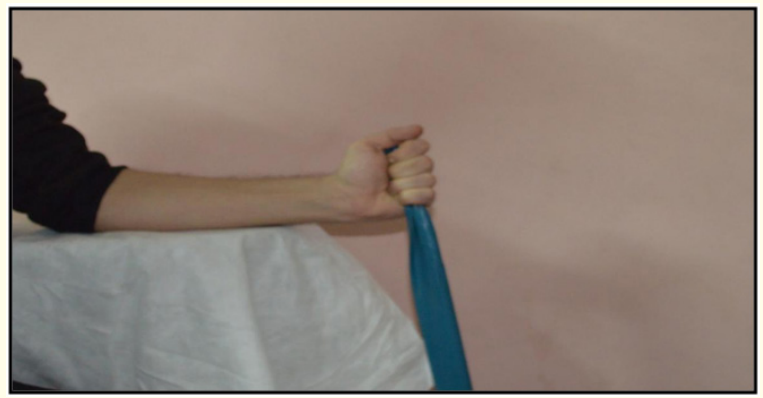

Figure 12: Wrist radial deviation against an elastic band.

At the end of the session gentle stretching exercises for wrist flexors and wrist extensors muscles will be done.

Step 3

Wrist extension with ulnar deviation against resistance

Patient was in sitting position, elbow semiflexed, forearm pronated and rested on the treatment table. The investigator's one hand supports the wrist and the other hand is placed on the dorsal surface at side of little finger and presses the hand down word toward the thumb. The patient was instructed to extend his wrist with ulnar deviation toward little finger. The exercise was performed as the patient counted to eight and relaxed. 


\section{Wrist extension with radial deviation against resistance}

Patient was in sitting position, elbow semiflexed, forearm pronated and rested on the treatment table. The investigator's one hand supports the wrist and the other hand is placed on the dorsal surface at side of the thumb finger and presses the hand down word toward the little finger. The patient was instructed to extend his wrist with radial deviation toward thumb. The exercise was performed as the patient counted to eight and relaxed (Figure 13).

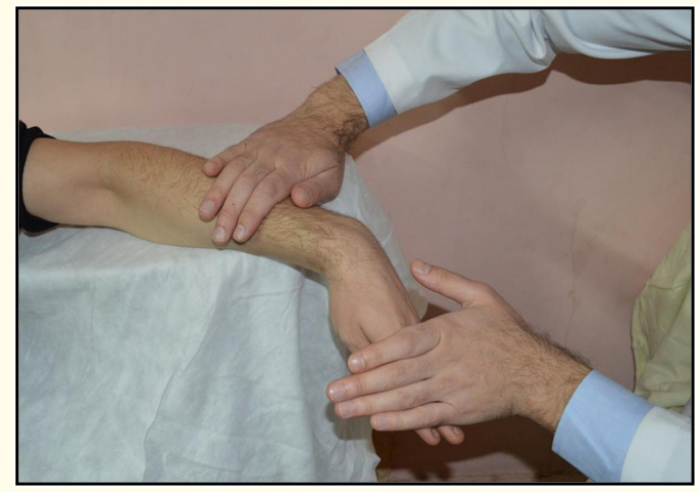

Figure 13: Wrist extension with radial deviation against resistance.

\section{Wrist flexion with ulnar deviation against resistance}

Patient was in sitting position, elbow semiflexed, forearm supinated and rested on the treatment table. The investigator's one hand supports the wrist and the other hand is placed on the palmer surface at side of the little finger and pushes the hand upward toward the thumb. The patient was instructed to flex his wrist with ulnar deviation toward the little finger. The exercise was performed as the patient counted to eight (Figure 14).

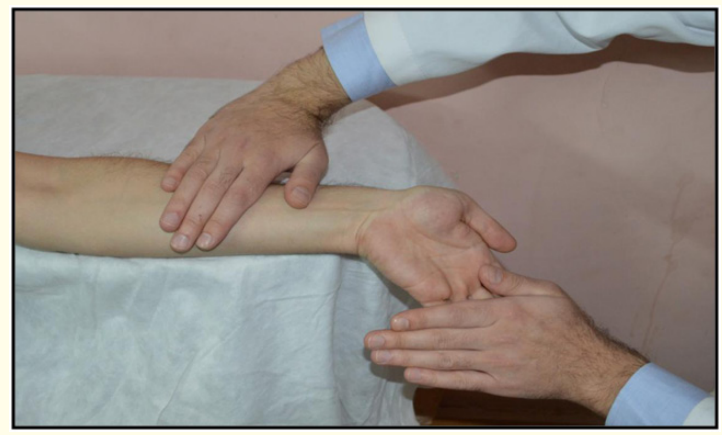

Figure 14: Resisted wrist flexion with ulnar deviation.

\section{Wrist flexion with radial deviation against resistance}

Patient was in sitting position, elbow semiflexed, forearm supinated and rested on the treatment table. The investigator's one hand supports the wrist and the other hand is placed on the palmer surface at side of the thumb finger and pushes the hand upward toward the little finger. The patient was instructed to flex his wrist with radial deviation toward the little finger. The exercise was performed as the patient counted to eight (Figure 15).

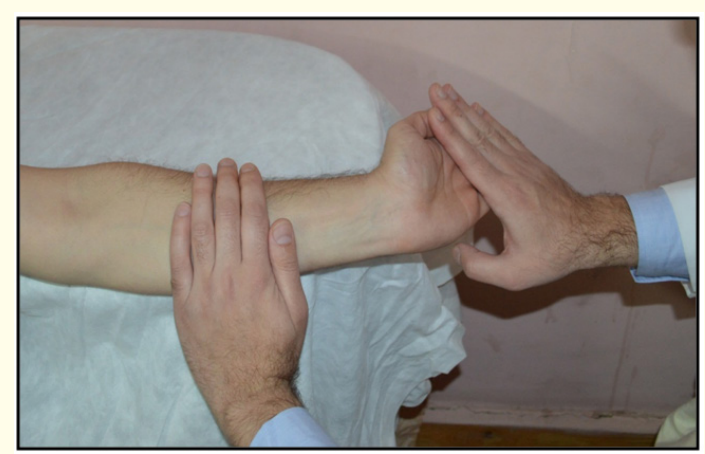

Figure 15: Resisted wrist flexion with radial deviation.

\section{Press hands against a wall (wall push ups)}

Patient was in standing position, elbow flexed, forearms pronated. The patient was instructed to push the wall with both hands. The exercise was performed as the patient counted to eight (Figure 16).

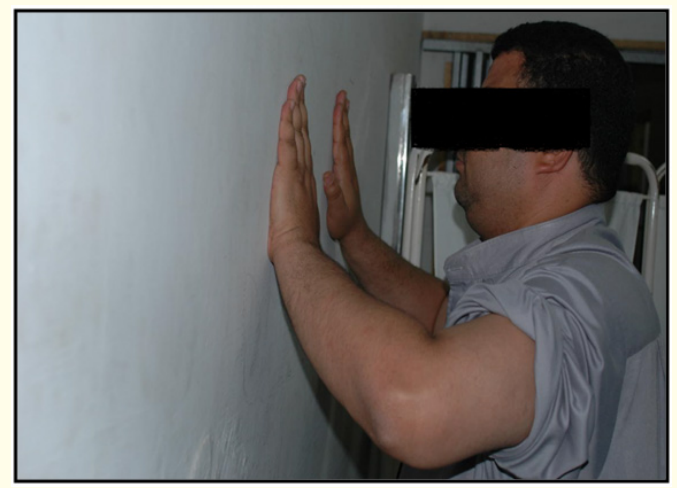

Figure 16: Press hands against a wall.

At the end of the session gentle stretching exercises for wrist flexors and wrist extensors muscles were made. 


\section{Step 4}

\section{Soft ball compressing exercises}

An occupational training program, including soft ball compressing exercises, transferring buttons from cup into another (Figure 17).

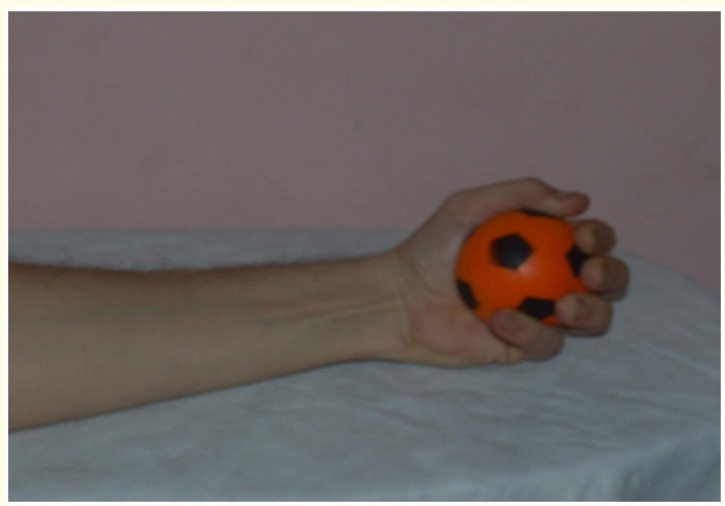

Figure 17: Soft ball compressing.

\section{Twisting a towel into a roll}

Patient was in sitting position, elbow extended. The patient was instructed to twist a towel into a roll with both hands. This exercise was performed as the patient counted to eight (Figure 18).

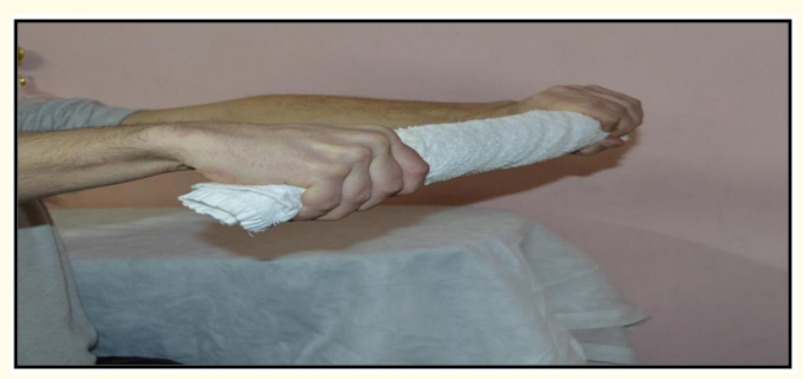

Figure 18: Twisting a towel into a roll.

Forearm supination and pronation on the treatment table in both directions

Patient was in sitting position, elbow flexed, and forearm rested on the treatment table. The patient was instructed to supinate his forearm from pronated position and also pronate forearm from supination. This exercise was performed as the patient counted to eight (Figure 19 and 20).

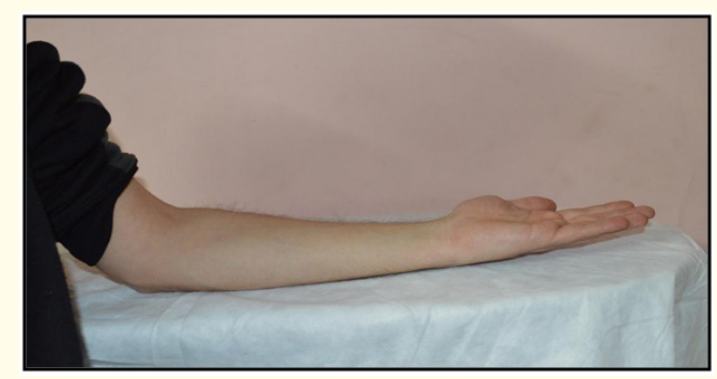

Figure 19: Forearm supination.

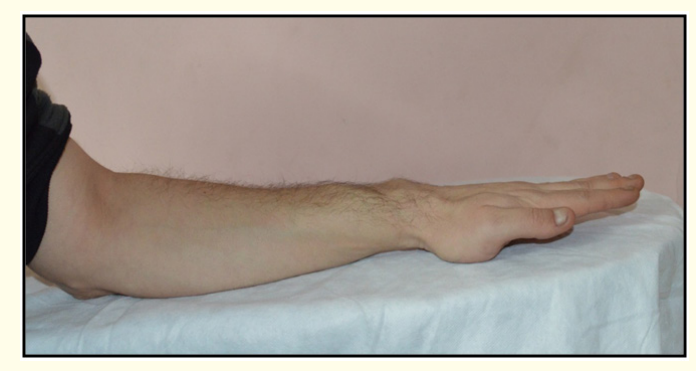

Figure 20: Forearm pronation.

At the end of the session gentle stretching exercises for wrist flexors and wrist extensors muscles will be done.

\section{Results}

The purpose of this study was to investigate the difference between the effect of forearm band and wrist splint combined with an exercises program on pain and grip strength in patient with tennis elbow.

\section{General characteristics of the subjects:}

In this study, 30 patients with tennis elbow were assigned randomly into two groups 15 patients in each group:

- $\quad$ Group (A): Fifteen patients were included in this group. The data in table 1 and figure (22-25) represented their mean age $(44.8 \pm 6.87)$ years, mean weight ( $84.0 \pm 10.81)$ kilograms (Kg), mean height (166.66 \pm 8.94$)$ centimeters $(\mathrm{cm})$, and mean BMI $(30.32 \pm 3.91) \mathrm{Kg} / \mathrm{m}^{2}$. 
- Group (B): Fifteen patients were included in this group. The data in table 1 and figure 21-24 represented their mean age (42.86 \pm 6.34$)$ years, mean weight (84.13 \pm 10.94$)$ kilograms (Kg), mean height $(169.6 \pm 7.19)$ centimeters $(\mathrm{cm})$, and mean BMI $(29.18 \pm 2.87) \mathrm{Kg} / \mathrm{m}^{2}$.

\begin{tabular}{|l|c|c|c|c|c|}
\hline \multirow{2}{*}{$\begin{array}{l}\text { General } \\
\text { charac- } \\
\text { teristics }\end{array}$} & Group A & Group B & \multicolumn{2}{|c|}{ Comparison } & \\
\cline { 2 - 6 } & Mean \pm SD & Mean \pm SD & $\begin{array}{c}\text { t- } \\
\text { value }\end{array}$ & $\begin{array}{c}\text { P- } \\
\text { value }\end{array}$ & S \\
\hline Age (yrs) & $44.8 \pm 6.87$ & $42.86 \pm 6.34$ & 0.8 & 0.43 & NS \\
\hline $\begin{array}{l}\text { Weight } \\
(\text { Kg) }\end{array}$ & $84.0 \pm 10.81$ & $84.13 \pm 10.94$ & 0.03 & 0.97 & NS \\
\hline $\begin{array}{l}\text { Height } \\
(\mathrm{cm})\end{array}$ & $166.66 \pm 8.94$ & $169.6 \pm 7.19$ & 0.98 & 0.33 & NS \\
\hline $\begin{array}{l}\text { BMI }(\mathrm{Kg} / \\
\left.\mathrm{m}^{2}\right)\end{array}$ & $30.32 \pm 3.91$ & $29.18 \pm 2.87$ & 0.9 & 0.37 & NS \\
\hline
\end{tabular}

Table 1: General characteristics of patients in both groups (A and B).

*SD: standard deviation, P: probability, S: significance, NS: non-significant.

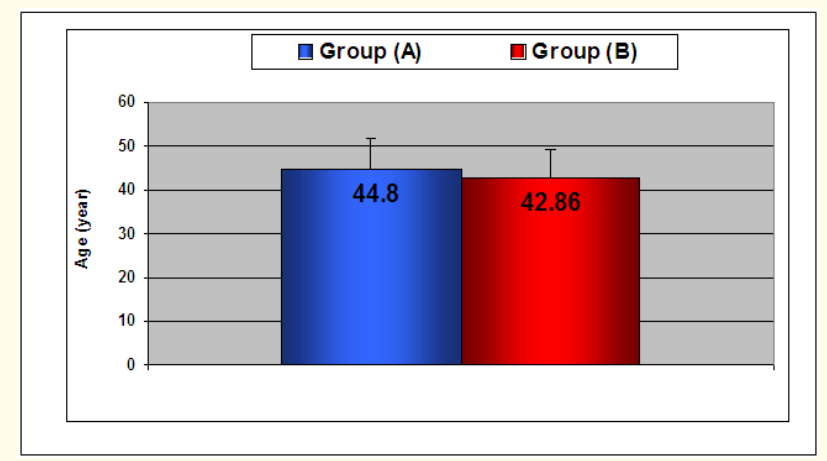

Figure 21: Mean and \pm SD of the age for groups $(A, B)$.

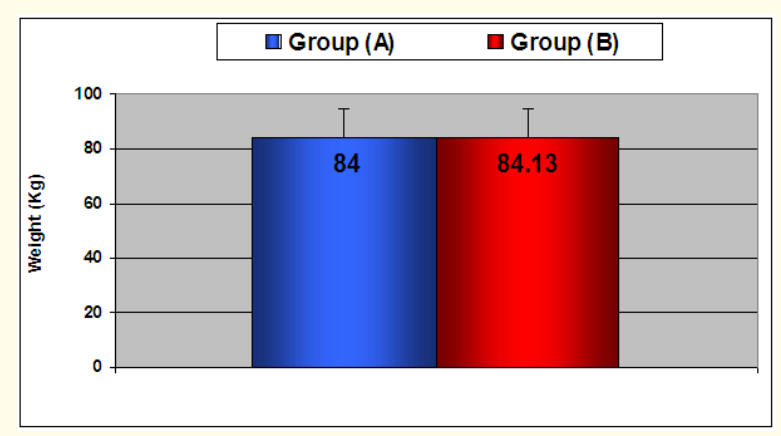

Figure 22: Mean and \pm SD of the weight for groups (A, B).

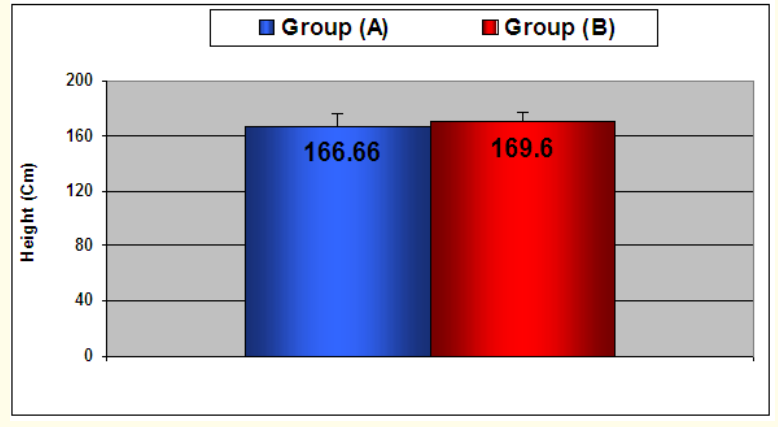

Figure 23: Mean and \pm SD of the height for groups $(A, B)$.

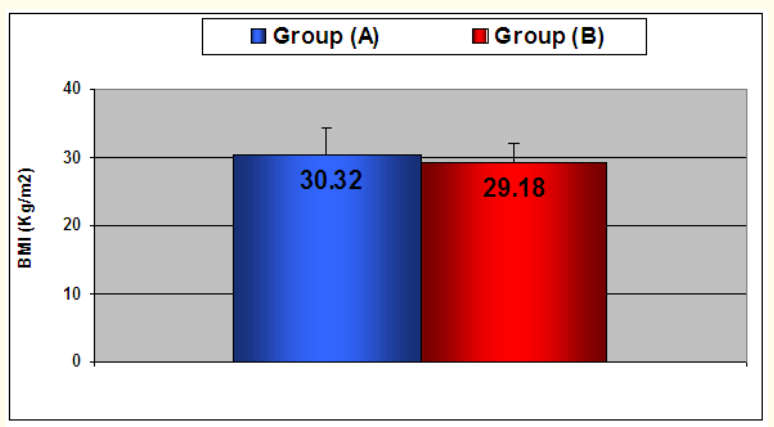

Figure 24: Mean and \pm SD of the BMI for groups $(A, B)$.

There was no significant difference between both groups in their ages, weights, heights, and BMI where their $\mathrm{t}$ and P-values were $(0.8,0.43),(0.03,0.97),(0.98,0.33)$, and $(0.9,0.37)$ respectively.

\section{Within subjects}

Table 2 demonstrated within subjects (Repeated measures) MANOVA test for the dependent variables pre and post treatment in both groups.

In group (A) repeated measures MANOVA revealed that there was a significant effect of treatment (forearm band and exercises) on the combined dependant variables where the $F$ value was (356.78) and the p value was (0.0001) as shown in table 2 .

In group (B) repeated measures MANOVA revealed that there was a significant effect of treatment (wrist splint and exercises) on the combined dependant variables where the F value was (305.41) and the $\mathrm{p}$ value was (0.0001) as shown in table 2 .

For the analysis of each dependant variable the univariate test was conducted using a Bonferroni adjusted alpha level of 0.025 $(0.05 / 2)$ as shown in table 3. 


\begin{tabular}{|l|c|c|c|}
\hline \multirow{2}{*}{ Group } & \multicolumn{3}{|c|}{ MANOVA Test } \\
\cline { 2 - 4 } & F-value & P-value & Significance \\
\hline Group (A) & 356.78 & 0.0001 & S \\
\hline Group (B) & 305.41 & 0.0001 & S \\
\hline
\end{tabular}

Table 2: Repeated measures MANOVA test for the dependant variables pre and post treatment in both groups.

* P: Probability, S: Significant
For group (A) there was a significant difference between pre and post treatment pain level as the pain level pre treatment was $(7.93 \pm 0.79)$ and for post treatment was $(4.53 \pm 0.74)$ where the F-value was (252.87) and P-value was (0.0001) with a percentage of improvement $42.87 \%$, and there was a significant difference between pre and post treatment hand grip strength as hand grip strength pre treatment was $(12.34 \pm 3.28)$ and for post treatment was $(21.56 \pm 2.71)$ where the F-value was (152.75) and P-value was $(0.0001)$ with a percentage of improvement $74.63 \%$ as shown in table 3 and figure 25.

\begin{tabular}{|c|c|c|c|c|c|c|}
\hline \multirow{2}{*}{ Group } & \multirow{2}{*}{ Variable } & Pre treatment & Post treatment & \multicolumn{3}{|c|}{ Univariate Test } \\
\cline { 2 - 7 } & & Mean \pm SD & Mean \pm SD & F-value & P-value & Significance \\
\hline \multirow{2}{*}{ Group (A) } & Pain level & $7.93 \pm 0.79$ & $4.53 \pm 0.74$ & 252.87 & 0.0001 & $\mathrm{~S}$ \\
\cline { 2 - 8 } & Hand grip strength & $12.34 \pm 3.28$ & $21.56 \pm 2.71$ & 152.75 & 0.0001 & $\mathrm{~S}$ \\
\hline \multirow{2}{*}{ Group (B) } & Pain level & $7.86 \pm 0.99$ & $3.73 \pm 0.7$ & 463.93 & 0.0001 & $\mathrm{~S}$ \\
\cline { 2 - 8 } & Hand grip strength & $12.63 \pm 3.09$ & $21.42 \pm 2.79$ & 182.83 & 0.0001 & $\mathrm{~S}$ \\
\hline
\end{tabular}

Table 3: Mean and \pm SD, and univariate test between pre and post treatment of the dependant variables in each group. *SD: Standard Deviation, P: Probability, S: Significant.

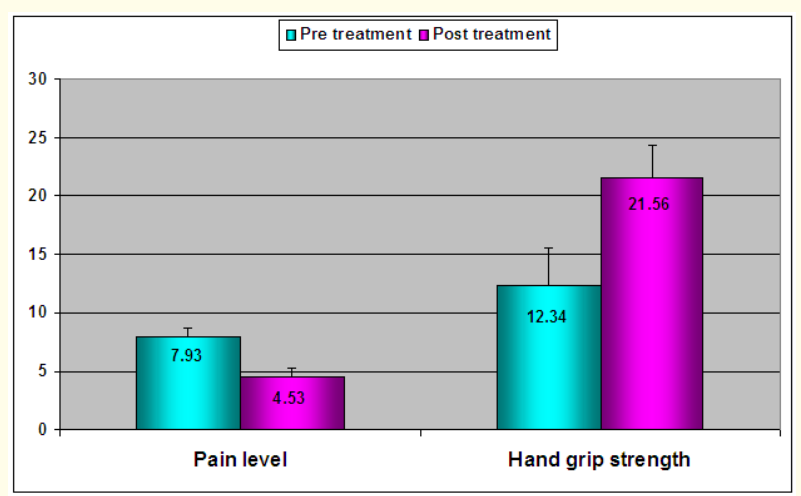

Figure 25: Mean and \pm SD of dependant variables for group (A).

For group (B) there was a significant difference between pre and post treatment pain level as the pain level pre treatment was $(7.86 \pm 0.99)$ and for post treatment was $(3.73 \pm 0.7)$ where the F-value was (463.93) and P-value was (0.0001) with a percentage of improvement $52.54 \%$, and there was a significant difference between pre and post treatment hand grip strength as hand grip strength pre treatment was $(12.63 \pm 3.09)$ and for post treatment was $(21.42 \pm 2.79)$ where the F-value was (182.83) and P-value was $(0.0001)$ with a percentage of improvement $69.59 \%$ as shown in table 3 and figure 26.

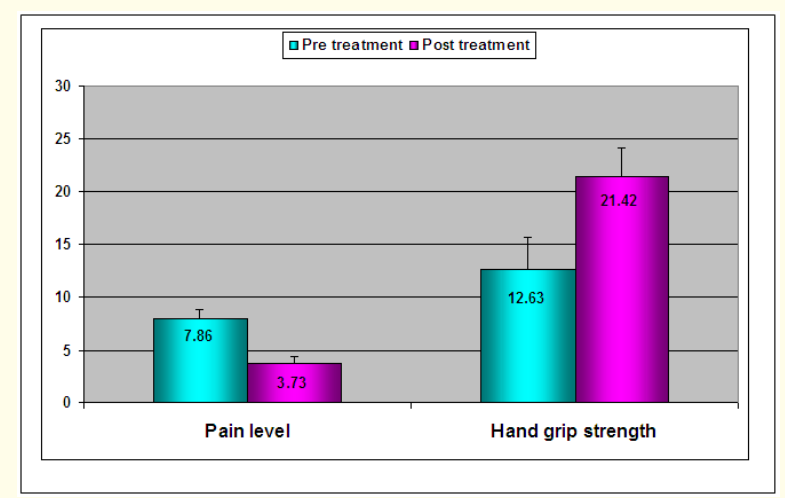

Figure 26: Mean and \pm SD of dependant variables for group (B).

\section{Between groups}

Table 4 demonstrated between subjects MANOVA test for the dependant variables pre and post treatment in both groups. 
Pre treatment between subjects MANOVA revealed that there was no significant difference between groups (A) and (B) in the combined dependant maybe dependent? variables where the $\mathrm{F}$ value was (0.04) and the p value was (0.95) as shown in table 4.

Post treatment between subjects MANOVA revealed that there was a significant difference between groups (A) and (B) in the combined dependant maybe dependent? variables where the $\mathrm{F}$ value was (4.45) and the p value was (0.02) as shown in table 4.

\begin{tabular}{|c|c|c|c|}
\hline \multirow{2}{*}{$\begin{array}{c}\text { Time of } \\
\text { measurements }\end{array}$} & \multicolumn{3}{|c|}{ MANOVA Test } \\
\cline { 2 - 4 } & F-value & P-value & Significance \\
\hline Pre treatment & 0.04 & 0.95 & NS \\
\hline Post treatment & 4.45 & 0.02 & $\mathrm{~S}$ \\
\hline
\end{tabular}

Table 4: Between subjects MANOVA test for the dependant variables pre and post treatment in both groups.

* P: Probability, S: Significant
For the analysis of each dependant maybe dependent? variable the univariate test was conducted using a Bonferroni adjusted alpha level of $0.025(0.05 / 2)$ as shown in table 5 .

Pre treatment there was no significant difference between group (A) and (B) in pain level where the F-value was (0.04) and P-value was (0.84), and there was no significant difference between group (A) and (B) in hand grip strength where the F-value was (0.06) and $\mathrm{P}$-value was (0.8) as shown in table 5 and figure 27.

Post treatment there was a significant difference between group (A) and (B) in pain level where the F-value was (9.16) and P-value was (0.005), while there was no significant difference between group (A) and (B) in hand grip strength where the F-value was (0.01) and P-value was (0.89) as shown in table 5 and figure 28.

\begin{tabular}{|l|c|c|c|c|c|c|}
\hline \multirow{2}{*}{ Time of measurements } & \multirow{2}{*}{ Variable } & Group (A) & Group (B) & \multicolumn{3}{|c|}{ Univariate Test } \\
\cline { 2 - 8 } & & Mean \pm SD & Mean \pm SD & F-value & P-value & Significance \\
\hline \multirow{2}{*}{ Pre treatment } & Pain level & $7.93 \pm 0.79$ & $7.86 \pm 0.99$ & 0.04 & 0.84 & NS \\
\cline { 2 - 8 } & Hand grip strength & $12.34 \pm 3.28$ & $12.63 \pm 3.09$ & 0.06 & 0.8 & NS \\
\hline \multirow{2}{*}{ Post treatment } & Pain level & $4.53 \pm 0.74$ & $3.73 \pm 0.7$ & 9.16 & 0.005 & S \\
\cline { 2 - 8 } & Hand grip strength & $21.56 \pm 2.71$ & $21.42 \pm 2.79$ & 0.01 & 0.89 & NS \\
\hline
\end{tabular}

Table 5: Mean and \pm SD, and univariate test of the dependant maybe dependent? variables for both groups.

*SD: Standard Deviation, P: Probability, S: Significant, NS: Non Significant.

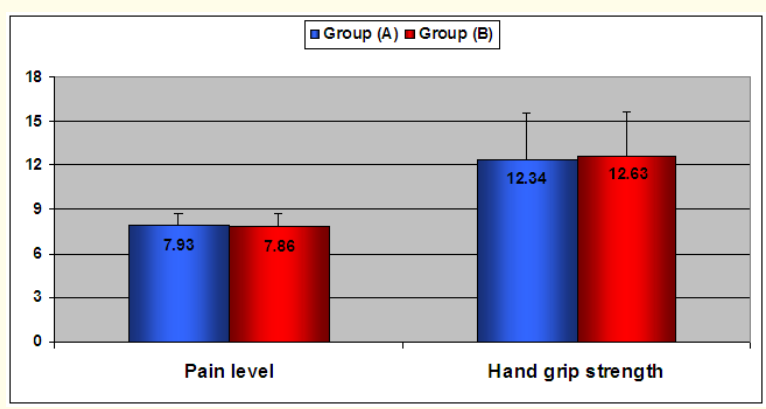

Figure 27: Mean and \pm SD of dependant variables pre treatment in each group.

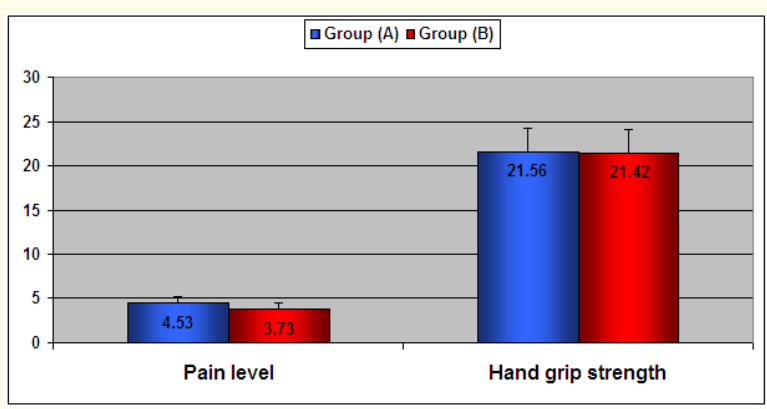

Figure 28: Mean and \pm SD of dependant variables post treatment in each group. 


\section{Discussion}

The purpose of this study was comparison between the effects of forearm support band and wrist splint on improvement of pain intensity and hand grip strength in patient with tennis elbow. Restoring full function in the wrist and the hand is the major goal of lateral epicondylitis rehabilitation.

The current study revealed that forearm support band or wrist splint combined with exercises for four weeks in patients with tennis elbow resulted in significant increase in hand grip strength in the post-treatment, associated with a significant decrease in pain intensity in the post-treatment in both groups. In addition, it revealed that there was significant difference between forearm support and wrist splint as regard to pain reduction, as wrist splint allows a greater degree of pain relief than the forearm support band. While there was no significant difference as regard to grip strength between both groups.

Thirty patients with lateral epicondylitis aged 30 to 55 years, were assigned into two groups, subjects in the first group (A) received forearm support band combined with exercises (12 session, 3 session per week). Subjects in second group (B) received wrist splint combined with the same exercises (12 session, 3 session per week). Pain severity and grip strength were assessed before and after four weeks of treatment for both groups.

All patients in both groups had symptoms of tennis elbow, with pain over the lateral aspect of the elbow that is aggravated by wrist extension and direct palpation over the lateral epicondyle of the humerus [25].

The result of this study agreed with several studies which investigated the pain severity using visual analog scale [8,26-28].

\section{Group of patients using forearm support}

From statistical analysis of pre and post treatment of pain assessment in patients who received Forearm support band, there was a significant difference of pain intensity value between pretreatment value and post-treatment value. Also, there was a significant difference of hand grip strength value between pre-treatment value and post-treatment value.

To examine the effect the forearm support band before and after treatment results of pain was measured with a visual analogue scale. There was significant decrease of pain intensity after treatment.
This effect on pain can be explained as suggested by Mark and Richard [29] that the forearm support band providing dispersive pressure around the area of inflammation, the brace serves to broaden the area of applied stress to the common extensor tendon origin, thus, lessening the stress on the muscular attachment at the lateral epicondyle; and by providing a restraint to full muscular expansion, the brace diminishes the potential force that the muscle can generate and thereby reducing pain.

The results of this study was supported with several studies suggested that forearm support band is frequently prescribed to produce a "counterforce" to reduce the load on the common extensor tendon and thereby reducing pain [9,30-32].

Several studies reported decrease in pain at the lateral epicondyle using the forearm support band. Solveborn [33], Van de Streek., et al. [6], Demneh and Jafarian [3] reported significant decrease in pain severity of tennis elbow patients using the forearm support band.

Only the study by Wuori., et al. [18] reported no decrease of pain with using the band. Furthermore, subjects reported increase in pain during contraction with using the band. This may be due to the type of bands that were used in this study.

To examine the effect the forearm support band on grip strength pre and post treatment using handheld dynamometer. There was significant improvement in grip strength after treatment.

Grip strength is considered the most valid outcome measure for lateral epicondylitis. At this study grip strength was assessed by handheld dynamometer. This finding was supported by the finding of Davidson., et al. [26], Kochar and Dogra [27], Smidt., et al. [8], and Struijis., et al [28].

The increased grip strength with using the forearm support band in tennis elbow patients may explained that the band caused direct and/or indirect facilitation to the muscle. Direct facilitation through direct pressure on the muscle, and indirect by stimulating the skin over the muscle. Wadsworth., et al. [34] suggested that use of the forearm support band caused decrease of the patients pain and subsequently decreased reflex inhibition of the wrist extensors that pain causes and allowed the patient to contract more forcefully. 
Biomechanical studies have shown that a forearm orthosis can decrease the forces acting at the ECRB origin if the pressure pad is placed over the belly of the ECRB, but tends to be more effective if the pressure pad is positioned distal to the lateral epicondyle $[31,35]$.

Several studies reported improve in grip strength in tennis elbow patients with band; Haker and Lundeberg [36] Erturk., et al. [37], Van de Streek., et al. [6], Struijs., et al. [7] reported significant increased in grip strength of tennis elbow patients with using the forearm support band.

Jafarian., et al. [9] reported Pain-free grip-strength is greater when using the elbow strap or the elbow sleeve orthosis compared to when using the placebo control orthosis. Knebel., et al. [2] found that using the band increased the mechanical muscle fatigue in normal subjects. This may be due to the increased activity of the motor neurons that are not under the effect of the band.

\section{Group of patients using wrist splint}

From statistical analysis of pre and post treatment of pain assessment in patients received wrist splint, there was a significant difference of pain intensity value between pre-treatment value and post-treatment value. Also, there was a significant difference of hand grip strength value between pre-treatment value and posttreatment value.

To examine the effect wrist splint pre and after treatment results of pain was measured with a visual analogue scale. There was significant decrease of pain intensity after treatment.

The decreased in pain intensity with using wrist splint in tennis elbow patients may be explained as suggested by Rosenberg., et al. [38] and Dutton [39] that the Wrist splint holds the wrist joint in slight extension. Using an extension wrist splint is thought to alleviate pain by reducing stress on the common extensor muscles and especially the extensor carpi radialis brevis (ECRB), by providing passive assistance to wrist extension that is necessary to counteract the wrist flexion forces that occur with gripping.

Also, This results was supported by Van de streek., et al. [17] who suggested that the splint forces the extensor muscles of the lateral epicondyle to relax. Expansion is completely limited and no force can be developed by muscle fibers. The overload forces are maximally reduced and the extensor tendons have the opportunity to recover. this way, the pain is thought to decrease.
Several studies reported decrease in pain at the lateral epicondyle with using the wrist splint; Caroline., et al. [40], Van Elk., et al. [10], Altan and Kanat [41], Demneh and Jafarian [3] reported similar pain relief effects when the wrist is kept in a resting position with wrist splint.

Regarding hand grip strength, the finding of the current study showed that there was significant improvement of hand grip strength with using the wrist splint.

This effect on grip strength can be explained as suggested by van Elk., et al [10]. The increased strength might have resulted from adapting the desired position in patients with lateral epicondylitis. The ECRB is primarily involved in stabilizing the wrist joint in extension, through their synergistic and fixator role. In chronic lateral epicondylitis these muscles cannot act optimally due to micro-tearing and excessive scarring at their origin. The splint supported the wrist passively in extension thus, improved their active participation.

This results was supported by Bhargava., et al. [42] reported that the grip strength was increased with using the wrist splint and found to be more at $15^{\circ}$ of wrist extension than $35^{\circ}$ when using wrist splint. Thus, at this position the wrist extensors showed a greater advantage for gripping

\section{Comparison between groups after treatment}

Comparing between the effect of forearm support band and wrist splint on lateral epicondylitis. After treatment there was significant difference between forearm support and wrist splint as regard to pain reduction as wrist splint allows a greater degree of pain relief than the forearm support band for patients with lateral epicondylitis, in addition, there was no significant difference between forearm support and wrist splint as regard to grip strength improvement.

This difference in degree of pain relief can be explained and supported by Garg., et al. [43] who reported that wrist extension splint allows a greater degree of pain relief than does the forearm strap brace for patients with lateral epicondylitis. Significant pain relief with the wrist extension splint may be due to improved immobilization of the wrist extensor muscles in a resting position, it gives more resting and more reduction of pain. 
In agreement with the results of the current study Altan and Kanat [41] comparing of the two groups showed significantly better improvement in resting pain in wrist splint when compared with forearm support band.

The study by Haker and Lundeberg [36] that reported no differences found between the cock-up splint and the elbow band. This may be due to the newly designed cock-up giving more rest to the extensors of the wrist than the old designed cock-up splint and therefore would be more effective.

Also, comparing between the effect of forearm support band and wrist splint on lateral epicondylitis. After treatment there was no difference between forearm support and wrist splint as regard to grip strength improvement.

Grip strength improved over the duration of the trial and no difference was found between the two groups. One of the limitations of grip strength is its subjectivity, being reliant on patient effort, which may vary greatly between individuals.

\section{Exercises program}

In the current study, both groups treatment was combined with progressive stretching and strengthening exercises. Eccentric training results in tendon strengthening by stimulating mechanoreceptors in tenocytes to produce collagen, which is probably the key cellular mechanism that determines recovery form tendon injuries. In addition, eccentric training may induce a response that normalizes the high concentrations of glycosaminoglycans. It may also improve collagen alignment of the tendon and stimulate collagen cross-linkage formation, both of which improve tensile strength. It has also been proposed that the positive effects of exercise programmes for tendon injuries may be attributable to either the effect of stretching, with a lengthening of the muscle-tendon unit and consequently less strain experienced during joint motion, or the effects of loading within the muscle-tendon unit, with hypertrophy and increased tensile strength in the tendon also during eccentric training, the blood flow is stopped in the area of damage and this leads to neovascularization, the formation of new blood vessels, which improves blood flow and healing in the long term.

The results showed that exercise programme added to each treatment variables three times per week for four weeks may give good clinical results in a shorter period of time [4,24,44-48].

\section{Summary}

This study was designed to detect the effect of forarm support band in addition to progressive exercises and wrist splint in addition to the same exercises on treating lateral epicondylitis patients, and to compare both effects through detecting differences in pain intensity and hand grip strength.

Thirty patients suffering from unilateral lateral epicondylitis participated in this study; they were randomly assigned to either group A (forearm support band with exercises) and group B (wrist splint with the same exercises). Pain intensity (using visual analog scale) and hand grip strength (using handheld dynamometer) were assessed, pre-treatment and post-treatment for both groups. Therapeutically, patients of both groups received 12 sessions, 3 sessions every week for 4 weeks.

Experimentally, comparison of the results pre-treatment and post-treatment showed significant improvement in elbow pain and improvement in hand grip strength of both group, and there was significant difference between forearm support and wrist splint as regard to pain reduction which wrist splint allows a greater degree of pain relief than the forearm support band for patients with lateral epicondylitis. While there was no significant difference between forearm support and wrist splint as regard to grip strength improvement in both groups.

\section{Conclusion}

- $\quad$ Forearm support band combined with exercises was effective in improving pain intensity and increasing hand grip strength.

- Wrist splint combined with exercises was effective in improving pain intensity and increasing hand grip strength.

- $\quad$ There was significant difference between forearm support and wrist splint as regard to pain reduction where wrist splint allows a greater degree of pain relief than the forearm support band.

- There was no difference between the use Forearm support band and Wrist splint in improvement of hand grip strength.

\section{Recommendations}

- The results of the current study demonstrate forearm support band or wrist splint should be included in the rehabilitation of individuals with tennis elbow. 
- $\quad$ The results of this study recommended:

- $\quad$ Further research should be conducted to investigate and compare the effects of orthoses device with other types of treatment in patients with lateral epicondylitis.

- Further investigations to determine the effect of other types of orthoses in treatment of tennis elbow.

- $\quad$ Further survey studies to determine the prevalence of lateral epicondylitis in Egypt.

\section{Bibliography}

1. Thomas De Smedt., et al. "Lateral epicondylitis in tennis: update on aetiology, biomechanics and treatment". Sports Medicine 41 (2007): 816-819.

2. Knebel PT., et al. "Effects of the forearm support band on wrist extensor muscle fatigue". Journal of Orthopaedic and Sports Physical Therapy 29.11 (1999) 677-685.

3. Demneh E and Jafarian F. "The immediate effects of orthoses on pain in people with lateral epicondylalgia". Pain Research Treatment (2013): 353-597.

4. Stasinopoulos D., et al. "An exercise programme for the management of lateral elbow tendinopathy". British Journal of Sports Medicine 39 (2005): 944-947.

5. Brett M., et al. "Treatment of Tendinopathy". Clinical Orthopaedics and Related Research 466 (2008): 1539-1554.

6. Van de Streek MD., et al. "The effect of a forearm/hand splint compared with an elbow band as a treatment for lateral epicondylitis". Prosthetics and Orthotics International 28 (2004): 183-189.

7. Smidt N and van der Windt DA. "Tennis elbow in primary care". BMJ 333.7575 (2006): 927-928.

8. Smidt N., et al. "Corticosteroid injection, physiotherapy, or wait and see policy for lateral epicondylitis: a randomized controlled trial". The Lancet 359.9307 (2002): 657-662.

9. Jafarian FS., et al. "The immediate effect of orthotic management on grip strength of patients with lateral epicondylosis". Journal of Orthopaedic and Sports Physical Therapy 39.6 (2009): 484-489.

10. Van Elk N., et al. "The application of an external wrist extension force reduces electromyographic activity of wrist extensor muscles during gripping". Journal of Orthopaedic and Sports Physical Therapy 34.5 (2004): 228-234.
11. Faes M., et al. "Dynamic extensor brace for lateral epicondylitis". Clinical Orthopaedics and Related Research 442 (2006): 149-157.

12. Mary C Burns and Michael W Neumeister. "Orthoses for overuse disorders of the upper limb”. (2008): 287-296.

13. Cannon NM., et al. Rehabilitation center of Indiana: diagnosis and treatment manual for physicians and therapists, ed 4, Indianapolis, IN, The Hand Rehabilitation Center of Indiana (2001).

14. Jeffery A Dlabach., et al. "Lateral and medial epicondylitis in the overhead athlete". Operative techniques in Orthopedics 11 (2011): 46-54.

15. Juul-Kristensen B., et al. "Poorer elbow proprioception in patients with lateral epicondylitis than in healthy controls: A Cross-sectional study". Journal of Shoulder and Elbow Surgery 17 (2008): 72s-81s.

16. Simon B. "Elbow and arm pain". In: Clinical Sports Medicine, Brukner P and Khan K (Eds.), 3rd. McGraw-Hil professional, Sydney (2006): 289-307.

17. Struijs PA., et al. "Conservative treatment of lateral apicondylitis brace versus physical therapy or combination of both- A randomized clinical trial". Journal of Sports Medicine 32.2 (2004): 462-470.

18. Wuori J., et al. "Strength and pain measures associated with lateral epicondylitis bracing". Archives of Physical Medicine and Rehabilitation 79 (1998): 832-837.

19. Kolber M and Cleland J. "Strength test using hand held dynamometery". Physical Therapy Reviews 10 (2005): 99-112.

20. Bijur P., et al. "Reliability of the visual analog scale for measurement of acute pain". Academic Emergency Medicine 8.12 (2009): 1153-1157.

21. Meyer NJ., et al. "The effect of the forearm support band on forces at the origin of the extensor carpi radialis brevis: a cadaveric study and review of literature". Journal of Hand Therapy 15 (2002): 179-184.

22. Fedorczyk JM. "Therapists management of elbow tendonitis". In Hunter, Mackin, Callahan, editors: Rehabilitation of the hand and upper extremity 2.5 (2002).

23. Wang C-J and Chen H-S. "Shock wave therapy for patient with lateral epicondylitis". American Journal of Sports Medicine 30.3 (2002): 265-270. 
24. Pienimaki T., et al. "Progressive strengthening and stretching exercises and ultrasound for chronic lateral epicondylitis". Physiotherapy 82.9 (1996): 522-530.

25. Radpsand M. "Combination of manipulation, exercise and physical therapy for treatment of lateral epicondylitis". 32.2 (2009): 166-172.

26. Davidson J., et al. "The effect of acupuncture versus ultrasound on pain level, grip strength and disability in individuals with lateral epicondylitis: A pilot study". Physiotherapy 53 (2001): 195-202.

27. Kochar M and Dogra A. "Research report, effectiveness of a specific physiotherapy regimen on patients with tennis elbow, clinical study". Physiotherapy 88 (6): 333-341, 2002.

28. Struijs PA., et al. "Manipulation of the wrist for management of lateral epicondylitis: A Randomized pilot study". Physical Therapy 83.7 (2003): 608-616.

29. Mark A and Richard A. "The Effects of Counterforce Bracing on Forearm and Wrist Muscle Function". JOSPT 2 (1992): 87-91.

30. Selvier T and Wilson J. "Methods utilized in treating lateral epicondylitis". Physical Therapy Reviews 5 (2005): 117-124.

31. Walther M., et al. "Biomechanical evaluation of braces used for the treatment of epicondylitis". Journal of shoulder and elbow Surgery 11.2 (2002): 265-270.

32. Takasaki H., et al. "Strain reduction of the extensor carpi radialis brevis tendon proximal origin following the application of a forearm support band". Journal of Orthopaedic and Sports Physical Therapy 38 (2008): 257-261.

33. Solveborn SA. "Radial epicondylagia (tennis elbow): treatment with stretching or forearm support band. A prospective study with long-term follow-up including rang of motion measurement". Scandinavian Journal of Medicine and Science in Sports 7.4 (1997): 229-237.

34. Wadsworth TC. "Tennis elbow: Conservative, surgical, and manip ulative treatment”. British Medicine 1294 (1989): 621-623.

35. Kroslak M and Murrell GAC. "Tennis elbow counterforce bracing". Techniques in Shoulder and Elbow Surgery 8 (2007): 7579.

36. Haker and Lundeberg. "Elbow-band, splintage and steroids in lateral epicondylalgia (tennis elbow)”. Pain Clinic 6 (1993): 103-112.
37. Erturk H., et al. "The efficacy of different treatment regiments that are commonly used in tennis elbow". Journal of Rheumatology and Medical Rehabilitation 8 (1997): 298-301.

38. Rosenberg N., et al. "Comparison of two methods for the evaluation of treatment in medial epicondylitis: pain estimation vs grip strength measurements". Archives of Orthopaedic and Trauma Surgery 124.6 (2004): 363-365.

39. Dutton M. "Orthopaedic Examination, Evaluation, and Intervention”. New York, NY: McGraw-Hill (2004).

40. Caroline W., et al. "The effect of use of a wrist orthosis during functional activities on surface electromyography of the wrist extensors in normal subjects". Journal of Hand Therapy 10.4 (1997): 283-289.

41. Altan L and Kanat E. "Conservative treatment of lateral epicondylitis: comparison of two different orthotic devices". Clinical Rheumatology 27.8 (2008): 1015-1019.

42. Bhargava AS., et al. "Grip strength measurements at two different wrist extension positions in chronic lateral epicondylitiscomparison of involved vs. uninvolved side in athletes and non athletes: a case-control study". Sports Medicine, Arthroscopy, Rehabilitation and Technology 2 (2010): 22.

43. Garg R., et al. "A prospective randomized study comparing a forearm strap brace versus a wrist splint for the treatment of lateral epicondylitis". Journal of Shoulder and Elbow Surgery 19.4 (2010): 508-512.

44. Pienimaki T., et al. "Long- term follow-up of conservatively treated chronic tennis elbow patients. A prospective and retrospective analysis". Scandinavian Journal of Medicine and Science in Sports 30.3 (1998): 159-166.

45. Svernlov B., et al. "Non-operative treatment regime including eccentric training for lateral humeral epicondylagia". Scandinavian Journal of Medicine and Science in Sports 11 (2001): 328-334.

46. Nilsson P., et al. "A prospective pilot study of a multidisciplinary home training programme for lateral epicondylitis". Musculoskeletal care 5.1 (2006) 36-50.

47. Stasinopoulos D., et al. "Comparison of cyriax physiotherapy, A supervised exercise programme and polarized polychromatic non-coherent light (bioptron light) for treatment of lateral epicondylitis". British Journal of Sports Medicine 41 (2007): 61-62. 
48. Manias P and Stasinopoulos D. "A controlled clinical pilot trial to study the effectiveness of ice as a supplement to the exercise programme for the management of lateral elbow tendinopathy". British Journal of Sports Medicine 40 (2006): 81-85.

\section{Assets from publication with us}

- Prompt Acknowledgement after receiving the article

- Thorough Double blinded peer review

- Rapid Publication

- Issue of Publication Certificate

- High visibility of your Published work

Website: www.actascientific.com/

Submit Article: www.actascientific.com/submission.php Email us: editor@actascientific.com

Contact us: +919182824667 